\title{
Disasters and Climate Change Economics: - a New Journal for a Changing World
}

\author{
Ilan Noy $^{1} \cdot$ Shunsuke Managi $^{2} \cdot$ Stephane Hallegatte $^{3}$
}

Published online: 25 May 2017

(C) Springer International Publishing 2017

We are very happy to welcome you to a new journal, focusing on a comparatively new topic, at least for economists: The Economics of Disasters and Climate Change. The focus of this new journal is the economic study of disasters, of climate change, and of the interactions between the two. ${ }^{1}$

The Economics of Disasters and Climate Change aims to serve as an integrating platform; a platform that provides a meeting point for researchers, policy-makers, practitioners, and educators, and all others who are interested in the theoretical and applied (quantitative) aspects of the economics of climate change and disasters. It is the first journal to focus on these issues together.

These topics remain new and emerging. Disasters have been examined by social scientists possibly since the 1920 doctoral dissertation of Samuel Prince on the Halifax disaster, but Dacy and Kunreuther's (1969) book is maybe the first modern economic analysis of this topic. On climate change, while the basic concepts on the role of greenhouse gases have been known for a long time, our understanding of climatic trends and their anthropogenic origins only dates back to the 1970s. The first paper on the economics of climate change was also published at this time (Nordhaus 1977). The first Intergovernmental Panel on Climate Change (IPCC) report, published in 1990, discussed the physics and the social aspect of the issue.

However, beyond these few isolated papers and reports, economists have only started looking at climate change in earnest in the past decade (since Stern 2007), and on disasters since the new millennium - an interest that grew exponentially after a spate of catastrophic events during its first decade. An important turning point in the collective awareness of the link between the two is the more recent SREX report (IPCC 2012; Edenhofer et al. 2014).

\footnotetext{
${ }^{1}$ Most succinctly, the focus is all papers classified by the Journal of Economic Literature's (JEL) code Q54 $\underline{\text { (Climate } \bullet \text { Natural Disasters and Their Management } \bullet \text { Global Warming). }}$
}

Ilan Noy

Ilan.Noy@vuw.ac.nz

1 Victoria University of Wellington, Wellington, New Zealand

2 Kyushu University, Fukuoka, Japan

3 World Bank, Washington, DC, USA 
This interest in the economic aspects of disasters and climate grew further in recent years after the signing, in 2015, of the Sendai and Paris international agreements (on disaster risk reduction, and climate change, respectively), the links between these two international efforts, the global agreement on Sustainable Development, and the accompanying elucidation of the Sustainable Development Goals.

The Nationally Determined Contributions - commitments that practically all countries have made in the context of the Paris Agreement, both in terms of adaptation to and mitigation of climate change - offer an important policy platform for countries to improve their management of natural disasters and climate change. The economic analyses and methodologies this journal will publish aim to play a key role in supporting their design.

Today, there is a lot of interest from policymakers and the public in these topics, but the current collection of research being conducted 'gets lost in the noise', as papers are published in a large and diverse variety of journals. Providing a 'first-point-of-contact' for all who are interested in the many important questions and challenges that hazards and climate change throw at our societies is another aim of the new journal.

The scope of this journal includes disaster risk management, adaptation to climate change, and mitigation and energy policies. It is open to contributors from all the established fields of economics. Banking, behavioral, development, finance, game theory, health, international, labor, macro and micro theory, public, and all other fields of economics are relevant to this journal's interest in disasters and climate. In fact, we think that disasters and climate play a central role in areas such as health, public finance, labor markets, and development so that this journal should be of interest to the profession as a whole.

Extreme events and changing trends enable us to better understand the economic system. Disasters represent exogenous shocks to the socio-economic systems that may help shed light on the dynamics of the system, as well as on its behaviors out of equilibrium. They may also help provide answers to more general questions that have been vexing economists for a long time - one obvious example is research on risk preferences.

We also aim to encourage the publication of research in areas that have been under-investigated by economists till now. Three examples we are keenly interested in, for example, are catastrophic insurance markets, climate change adaptation, and the distributional impacts of climate policies. Our interpretation of the scope of this journal is fairly broad, and we are also interested in publishing economic research on related phenomena such as biological hazards and infectious diseases.

These topics, as so much else that economists focus on, is potentially politically contentious and widely and vociferously debated in the public arena. We are acutely aware of that, and as such, the only criterion we employ for the inclusion of papers is the intellectual rigor of the contribution. We are open to diverse viewpoints and approaches, analyses, and conclusions, so long as they are judged to be rigorous by our reviewers, editorial board member, and ourselves. It is useful to note, at this point, that many of the most respected economists working on these issues have graciously agreed to join the new journal's editorial board; and we plan to rely on them to provide the intellectual direction and rigor that we aim for.

We are concerned about the length of time it often takes for papers to be evaluated in Economics journals, and peek enviously at our colleagues in the natural and physical sciences whose wait for editorial decisions is measured in days and weeks, and not (as unfortunately has occasionally happened to all of us) in years. Our aim is to provide our authors with an initial decision in, at most, three months, and preferably significantly less than that. We also ask our referees not to micro-manage the papers they are assessing, and to 
insist only on revisions that significantly contribute to the strength of the analysis and without which the paper is unpublishable.

While our focus will be on high-quality, cutting-edge research, we also aim to publish review articles and policy/opinion pieces on relevant questions that arise out of the global research agenda. We hope this journal will consequently also hold appeal for researchers and practitioners in other related disciplines, especially in the social and political sciences and for the natural scientists who focus on hazards and climate change.

The first issue of this journal is constituted of a collection of papers that, we think, aptly demonstrate the breadth of topics and the depth of approaches we aim to cover in this journal. We hope you will join us in this journey, submit your papers to the journal, and read with interest what our colleagues have to say.

Sincerely,

The Editors

\section{References}

Dacy D, Kunreuther H (1969) The economics of natural disasters. The Free Press, New York

Edenhofer O, Pichs-Madruga R, Sokona Y, Farahani E, Kadner S, Seyboth K, Adler A, Baum I, Brunner S, Eickemeier P, Kriemann B, Salvolainen J, Schlömer S, von Stechow C, Zwickel T, Minx J (eds) (2014) Climate change 2014: Mitigation of climate change. Contribution of Working Group III to the Fifth Assessment Report of the IPCC. Cambridge University Press, Cambridge

IPCC (2012) Managing the risks of extreme events and disasters to advance climate change adaptation. Cambridge University Press, Cambridge

Nordhaus W (1977) Economic growth and climate: the carbon dioxide problem. Am Econ Rev 67(1):341-346 Stern N (2007) The economics of climate change: the Stern review. Cambridge University Press, Cambridge 